\title{
Numerical Modelling of the Sediment Re-Suspension Induced by Boat Traffic
}

\author{
Hassan Smaoui ${ }^{1,2}$, Abdellatif Ouahsine ${ }^{2}$, Damien Pham Van Bang ${ }^{1,3}$ and \\ Philippe Sergent ${ }^{1}$ and François Hissel ${ }^{1}$ \\ ${ }^{1}$ Centre d'Études Techniques Maritimes et Fluviales (CETMEF). 2, Bd Gambetta, B.P. \\ 60039, 60321 Compiègne Cedex \\ ${ }^{2}$ LHN, Laboratoire Roberval UMR 6253 CNRS, Université de Technologie de Compiègne, \\ B.P. 20529, 60206 Compiègne Cedex \\ ${ }^{3}$ EDF/RED, Laboratoire d'Hydraulique Saint Venant, 6, quai Watier, Bat K, B.P. 49, \\ 78401 Chatou Cedex \\ France
}

\section{Introduction}

Fluvial transport in inland waterways is used in France and Europe since millennia. It was the most effective transport mode for goods and merchandizes before the development of the terrestrial alternatives. As an illustration, the French network of the inland waterways counted $12800 \mathrm{~km}$ of both, rivers and channels, at the beginning of the twentieth century. The huge development of highways and railways encountered in France has progressively decreased the use of fluvial transport. By considering the duration for the transport, the terrestrial mode looks more attractive than the fluvial one. But, the actual context of climate change and the international or European commitments to strongly diminish $\mathrm{CO}_{2}$ emissions are pleading for the reverse modal transfer, i.e. from highways and/or railways to waterways. Rebalancing the different transport modes are indeed compatible with the sustainable development concepts facing against road saturation, $\mathrm{CO}_{2}$ emissions, visual or noise pollutions while ensuring a better safety.

Even through the shared awareness and the common efforts to increase the river traffic, this transport mode is still considered "under-developed" in the white paper of the European commission of 2001. For example, the fluvial transport in France has increased by $30 \%$ in ten years $(1997-2007)$, but it only represents 3\% of the means of transport. And the recent recommendations in "Grenelle de l'environnement" initiated by the French ministry of ecology may accelerate the rebalance between rails, roads and rivers, carrying the ambition of a $25 \%$ report from the road down to the river by 2020.

However, the development of this transport mode will certainly have economical and ecological consequences on the river management. The intensification of the river traffic by increasing the size and/or the frequency of passing boats will impact the actual management plan of the river. The waves induced by navigation could become stronger and bank erosion more frequent. The induced currents may be more intense and the resulting sediment transport more problematic. Indeed, it is accepted in aquatic environment that erosion 
phenomenon have strong consequences on the ecosystem : destruction of habitats, increase in the turbidity, release of nutritive elements (phosphorus and nitrogenizes) which support the proliferation of the algae. With these economical and environmental considerations, the benefit/cost balance for the maintenance program of the inland waterways is changed and some practices could be renewed in the light of recent investigations.

To evaluate how different passing boats impact on the waterway, it was measured at two fields the hydraulic conditions $(h, u)$ and the solid suspended matter (SSM, c) at different points. The measurements are related to the boat traffic that is obviously recorded or geo-localized. The two sites (canal de la Sensée and the Seine river: see figures 1 and 2) are investigated in November 2006. The water signals obtained close to the bank and the SSM concentrations close to the bed are measured at different points. The data description and analysis are fully presented in (Pham Van Bang et al., 2007). Most of the passing boats are impacting the waterway in modifying the water elevation and the turbidity that was frequency- or space-time analyzed by Pham Van Bang et al., 2008.

The field experiment aims to optimize maintenance program (dredging operations to maintain the nautical depth) and evaluate the effect of an increase in the boat frequentation. Due to the large scale of the site, it remains obvious the field measurements alone are not sufficient to quantify all the variables of the flow. For example, it is still not possible to measure in situ and non-intrusively the turbulent movement of both the water and the sediment. But during a boat episode, such measurements are missing, more particularly close to the bed or the bank of the studied river. These lacks of information is herein supplemented by the results of the mathematical/numerical models that enables a prediction, for inaccessible data field at least.

In this book chapter, we present the numerical approach for a 1DV model to predict the sediment re-suspension behind the boat passage. To proceed, we first start with the description of the mathematical model 1DV and justify the applicability to the sites of consideration. Then, we analyze the model results focusing both aspects, the TKE distribution along the vertical direction and the time-decrease in the fixed point measurement. In particular, we demonstrate the model is reliable to reproduce the field observed sediment re-suspension. Finally, we prove the numerical approach is effective to predict the sediment fluxes induced by the daily river traffic.

\section{Presentation of the mathematical model}

The model 1DV used in this study is part of a more general 3D model that is specifically devoted to free surface flows. The 1DV model is obtained by neglecting all the horizontal gradients, except the pressure gradient. It consists in these set of equations for the mean and turbulent movements and the continuity equation :

$$
\begin{gathered}
\frac{\partial u}{\partial t}+\frac{1}{\rho} \frac{\partial p}{\partial x}=\frac{\partial}{\partial z}\left[\left(v+v_{t}\right) \frac{\partial u}{\partial z}\right] \\
\frac{\partial k}{\partial t}=v_{t}\left(\frac{\partial u}{\partial z}\right)^{2}+\frac{\partial}{\partial z}\left[v_{t k} \frac{\partial k}{\partial z}\right]-\frac{k \sqrt{k}}{B_{1} L} \\
\frac{\partial k L}{\partial t}=A_{1} L v_{t}\left(\frac{\partial u}{\partial z}\right)^{2}+\frac{\partial}{\partial z}\left[v_{t k} \frac{\partial k L}{\partial z}\right]-\frac{L^{2} \sqrt{k}}{B_{2} \widetilde{w}}
\end{gathered}
$$




$$
\frac{\partial c}{\partial t}=w_{s} \frac{\partial c}{\partial z}+\frac{\partial}{\partial z}\left[\gamma_{t} \frac{\partial c}{\partial z}\right]
$$

where $t$ is the time, $x$ and $z$ are the horizontal and the vertical coordinates respectively, $u$ the horizontal velocity, $p$ the pressure, $\rho$ the water density, $v$ the molecular viscosity, $v_{t}$ the turbulent viscosity, $k$ the TKE (turbulent kinetic energy), $L$ the mixing length, $v_{t k}$ the turbulent diffusivity of the TKE, $\widetilde{w}$ is the wall function, $A_{1}, B_{1}, B_{2}$ are empirical constants (Table 1$), c$ the concentration of SSM, $\gamma_{t}$ the turbulent diffusivity of SSM and $w_{s}$ the settling velocity of sediment given by:

$$
w_{s}= \begin{cases}\frac{g d_{50}^{2}(s-1)}{18 v} & \text { if } d_{50}<63 \mu \mathrm{m} \\ \frac{-3 v+\sqrt{9 v^{2}+g d_{50}^{2}(s-1)\left(\alpha_{1}+\alpha_{2} d_{50}\right)}}{\beta_{1}+\beta_{2} d_{50}} & \text { if } d_{50} \geq 63 \mu \mathrm{m}\end{cases}
$$

Where $v$ is the molecular viscosity, $g$ is the acceleration of gravity, $d_{50}$ is the median diameter of the sediments, $s=\rho_{s} / \rho, \rho_{s}$ is the density of the sediments and $\alpha_{1}, \alpha_{2}, \beta_{1}, \beta_{2}$ are empirical constants (Table 2).

\begin{tabular}{|c|c|c|c|c|c|}
\hline$A_{1}$ & $B_{1}$ & $B_{2}$ & $S_{h}$ & $S_{k}$ & $S_{m}$ \\
\hline 1.80 & 16.6 & 12.48 & 0.49 & 0.20 & 0.39 \\
\hline
\end{tabular}

Table 1. Closure empirical constants of $k-k L$ turbulence model

\begin{tabular}{|c|c|c|c|}
\hline$\alpha_{1}(m)$ & $\alpha_{2}$ & $\beta_{1}(m)$ & $\beta_{2}$ \\
\hline $3.8691 \times 10^{-5}$ & $2.4801 \times 10^{-2}$ & $1.1607 \times 10^{-4}$ & $7.4405 \times 10^{-2}$ \\
\hline
\end{tabular}

Table 2. Empirical constants used to compute the settling velocity $w_{c}$

To close the system of equations $(1,2,3,4)$, the turbulent viscosity $v_{t}$ and diffusivities $\left(v_{t k}, \gamma_{t}\right)$ must be determined from TKE $(k)$, the mixing length $(L)$ and same stability functions $S_{m}, S_{k}$ and $S_{h}$ as :

$$
v_{t}=L \sqrt{k} S_{m} \quad, \quad v_{t k}=L \sqrt{k} S_{k} \quad, \quad \gamma_{t}=\frac{S_{h}}{S_{m}} v_{t}
$$

Values of the stability functions $S_{m}, S_{k}$ and $S_{h}$ are given by Blumberg \& Mellor, 1987 in Table (1).

\subsection{Bottom conditions}

At the bottom, a non-slip condition is assumed for the velocity $u\left(u\left(z_{0}\right)=0\right)$. Moreover, if we assume the equilibrium between the production and the dissipation of the TKE, the logarithmic profil of the velocity $u$ and a linear mixing length, the following conditions can be imposed for $k$ and $L$

$$
k\left(z_{0}\right)=\lambda_{b} u_{*}^{2} \quad, \quad L\left(z_{0}\right)=\kappa z_{0}
$$

where $\lambda_{b}$ is an empirical coefficient, $u_{*}$ is the bottom friction velocity, $\left(\lambda_{b}=6.74\right)$ and $\kappa$ is the von Karmàn constant $(\kappa=0.41)$.

The bottom condition for the equation (4) dealing with sediment conservation is expressed by equation (8). At the fluid-sediment bed interface, equation (8) assume the equilibrium 
between between the descending (or the deposition rate $D$ ) and the ascending (or the erosion rate $E$ ) sediment fluxes.

$$
\left(\gamma_{t} \frac{\partial c}{\partial z}+w_{s} c\right)_{z=z_{0}}=D-E
$$

The deposition rate $D$ is considered proportional to the SSM concentration close to the bed with the settling velocity $w_{s}$ acting as a proportionality factor $\left(D=w_{\mathcal{S}} c\left(z_{0}\right)\right)$. In addition, the erosion rate, E, is computed by the equation (9) given in the equilibrium condition by Celik \& Rodi,1984; Celik \& Rodi, 1988; Celik \& Rodi, 1991 and Van Rijn, 1986.

$$
E=w_{s} c_{b} \frac{\gamma_{0} S}{1+\gamma_{0} S}
$$

where $c_{b}$ is the volume concentration of the sediment $\left(c_{b}=0.65\right.$ for non-cohesive sediment), $\gamma_{0}$ is an empirical constant for the sediment re-suspension and $S$ is the non-dimensional shear stress excess given by:

$$
S=\frac{\tau_{b}-\tau_{t h}}{\tau_{t h}}
$$

$\tau_{b}=\rho u_{*}^{2}$ is the shear stress at the bottom and $\tau_{t h}$ the critical threshold for erosion.

\subsection{Free surface conditions}

At this interface (air-fluid), as a first approximation and without the effects of boat propellers, we consider that the velocity boats are transmitted directly by the shear effect to the surface layer. The effect of a boat passage is therefore taken into consideration by using the navigation velocity of boats as hydrodynamic forcing: $u(H)=V_{\text {boat }}$. However this first approximation is relevant since the navigation velocities of boats are measured accurately in the field conditions by using differential GPS systems.

The equilibrium between production-dissipation of the TKE, and a linear law for the mixing length are also assumed at $z=H$. Thus, the conditions to be imposed on the free surface are:

$$
k(H)=\lambda_{s} u_{*, s}^{2} \quad, \quad L(H)=\kappa z_{s}
$$

where $\lambda_{s}$ is an empirical coefficient, $u_{*, s}$ is the surface friction velocity and $z_{s}$ is the roughness of the boat surface.

Concerning the boundary condition for the sediment equation (4) at the free surface, it is specified a zero flux condition (i.e. no sediment flux across the free surface):

$$
\left(\gamma_{t} \frac{\partial c}{\partial z}+w_{\mathcal{S}} c\right)_{z=H}=0
$$

\subsection{Numerical solution}

The flow modeled in this study is sheared flow at the surface and boundary layer flow at the bottom. The variables of this type of flow are characterized by large variations in the vicinities of the boundaries of the domain. To reproduce numerically these variations, we used a variable mesh size by splitting the column water into three layers (bottom, intermediate layer and surface layer). The surface and bottom layers were meshed very fine (about one millimeter). To limit interpolation procedures during the computation, the mean variables $(u$, $c)$ and the turbulent variables $\left(k, L, v_{t}, \gamma_{t}\right)$ were calculated on two staggered grids. This grid 
shift allows us to express naturally the various gradients of each equation of system (1-4). Equations (1-4) with their boundary conditions was discretized by the finite volume method in space and finite differences in time. The spatial partial derivatives were approximated by a centered scheme except the convective term of equation (4) for which the upwind scheme was adopted. The implicit Euler scheme was adopted for the time derivatives of all model equations. Note that the discretization of equations has led to solving a tri-diagonal linear system by the Thoma's algorithm (TDMA: Tri-Diagonal Matrix Algorithm).

\section{Application of the 1DV model}

\subsection{Field measurements}

The impacts of passing boats on the bank erosion and/or the sediment re-suspension are specifically addressed during previous field experiments (Pham Van Bang et al., 2007 and 2008). Two sites (figures 1, 2) are considered: "Canal de la Sensée" (site 1) in northern France; Seine river (site 2). The two weeks (November 2006) measurements consist in records on the water elevations close to the bank and SSM concentrations with flow velocities in the vicinity of the bottom. The water fluctuations induced by the passing boats are measured by the mean of classical capacitive gauges in three points. This choice enables studies on the following aspects: the amplitude, the frequency and the direction of waves that are produced by the boat passage. The concentration and velocity measurements close to the bed are obtained by using Optical Backscattering Sensor, OBS, and electromagnetic velocity-meter, S4. Both sensors, OBS and S4, are attached to a beam that is anchored to the bed in the center of the navigation channel. The OBS is located at $10 \mathrm{~cm}$ above the sediment bed while the S4 is at $15 \mathrm{~cm}$. This experimental set-up is completed by Acoustic Doppler Current Profiler (ADCP) located behind the passing boat to measure the vertical profile of flow velocity. The backscattered acoustic signal from ADCP transducer is also analyzed since its intensity provides qualitative information on the SSM concentration. As far as this chapter deals with sediment re-suspension induced by passing boats, the analysis from boat wake and ADCP measurements (detailed in Pham Van Bang et al., 2007) are not considered in the present study and only measurements close to the bed (from S4 and OBS transducers) are of concern. The information provided by these sub-aquatic sensors are indeed more relevant to characterize the re-suspension of sediment. It is generally observed from OBS measurements the production of concentration peaks during the boats passage. Thereafter, the peak tends slowly to decrease after the boat passage. This could be explained by the non-negligible inertia of the water mass which delays the recovering of equilibrium as explained later

\subsection{Parameters and model forcing}

During the period of the field investigations on the two sites, the daily traffic is recorded in order to correlate measurements to the navigation parameters. Of prior importance, it is recorded the direction, speed, trajectory and type (size, draught) of boats by the use of DGPS, radar and/or digital camera (Pham Van Bang et al., 2007). For example, the navigation speed with the boat length is used to form a chronicle that is finally exploited to force the velocity $u$ at the free surface $z=H$.

The river bed and the SSM are sampled for the calibration of transducer, but also for the estimation of the bed roughness. Indeed, from grain size analysis of bed samples, it is determined a median diameter for the sediment particles, $d_{50}$, close to $20 \mu \mathrm{m}$ (site 1 ) and 40 $\mu m$ (site 2). This result enables the classification of the sediment as muddy sand for both sites. 


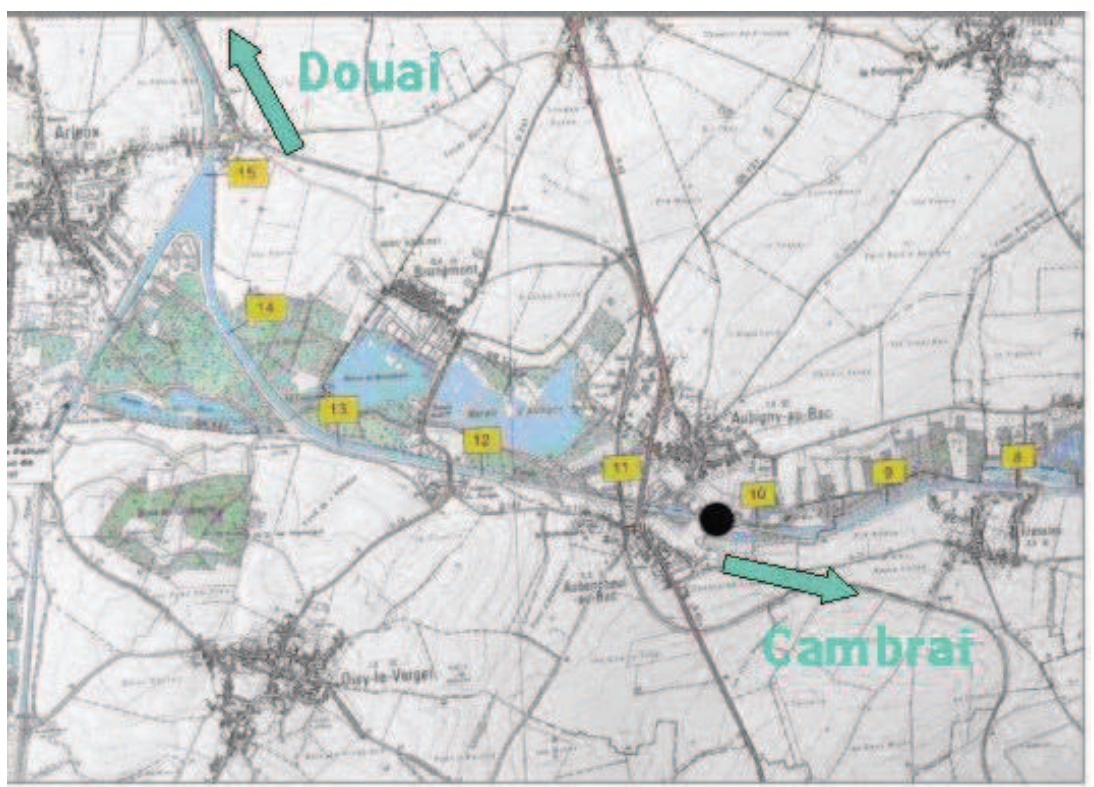

Fig. 1. Localization of the measurement site 1 "Canal de la Sensée" (North of France)

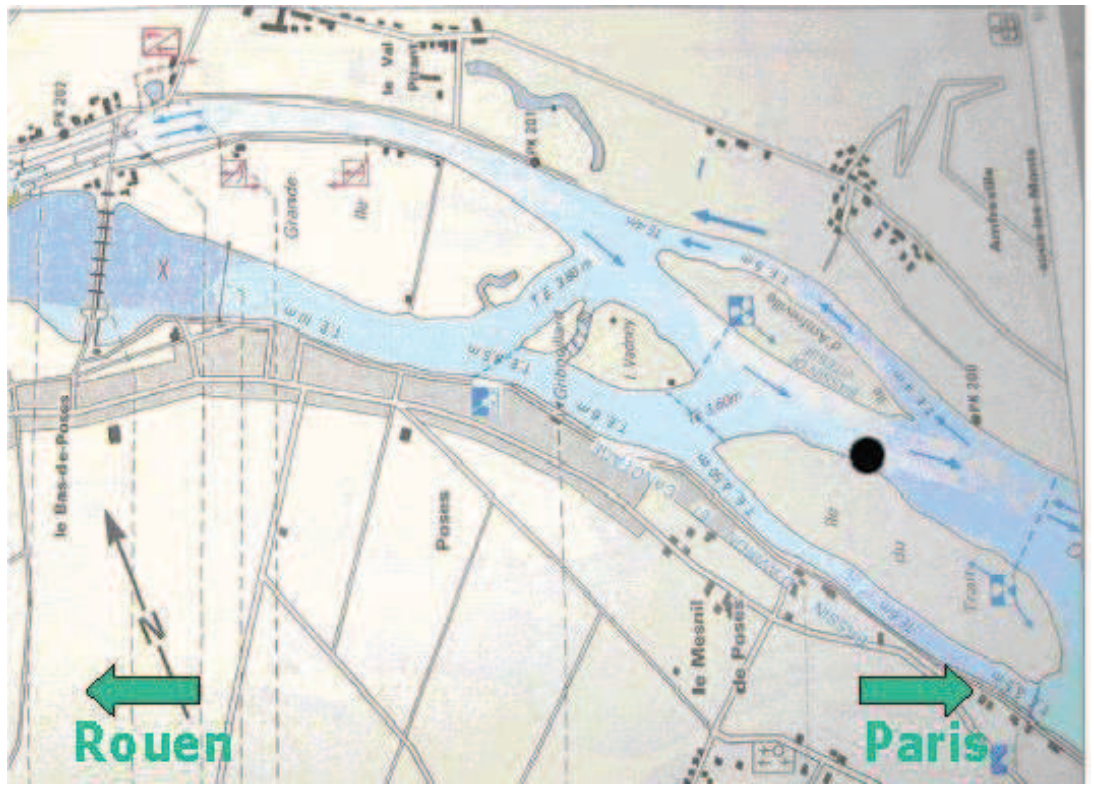

Fig. 2. Localization of the measurement site 2 "Seine river" (North of Paris, France) 
The median diameter, $d_{50}$, is finally used to estimate the roughness of the bottom according to $: z_{0} \cong 8 d_{50}$.

\section{Presentation of results simulations}

As mentioned above, the measurement campaign was conducted on two different sites over a period of two weeks. However, we present here, for example, simulations for some days of both site $1(11 / 08 / 2006$ and 11/09/2006) and site $2(11 / 15 / 2006)$.

\subsection{The current induced by the boats}

Figure 3 presents the velocity and the variables of turbulence obtained by the 1DV model. Two boat passages (namely D1 and D9, navigating down- and up-stream, see table (4)) are simulated for the day of the $11 / 08 / 2006$. On this figure, it is first to notice that the obtained vertical profile of velocity is in good agreement with the flow characteristic expected from the theory of the surface-boundary layer. Moreover, the numerical model reproduces realistically the return currents induced by boats (inversion of the profile): the vertical profiles of velocity provided by our model are in good agreement with available data (mostly from physical model at laboratory) on the flow characteristics in the under keel clearance region.

Figures 3.b, 3.c and 3.d show that the model provides vertical profiles of turbulence variables $\left(k, L, v_{t}\right)$ in perfect agreement with the theory of the turbulent surface boundary layer structure.

The 1DV model also enables to simulate the velocity measurements performed by $\mathrm{S} 4$ sensors that are localized at $10 \mathrm{~cm}$ and $25 \mathrm{~cm}$ from the bottom. For the boat traffic recorded during the day of the 11/08/2006 (site 1), the chronicle presents strong and irregular peaks that is explained by the important inertia of water which delays considerably the return to equilibrium. The averaged peaks in the velocity for the day of the $11 / 08 / 2006$ is $3.5 \mathrm{~cm} / \mathrm{s}$ at $z=10 \mathrm{~cm}$ and $4.4 \mathrm{~cm} / \mathrm{s}$ at $z=25 \mathrm{~cm}$. These estimations are in close agreement with the field measurements (Pham Van Bang et al., 2007, 2008).

For the site 2 (day 11/15/2006), the model provides a velocity of $12 \mathrm{~cm} / \mathrm{s}$ at $z=10 \mathrm{~cm}$ and 16 $\mathrm{cm} / \mathrm{s}$ at $z=25 \mathrm{~cm}$. This variation is undoubtedly due to the difference in the site conditions (geometry of the navigation channel, type of boat,..etc.). For example, the site 1 is localized at a narrow and straight channel (50 $\mathrm{m}$ wide, $4 \mathrm{~m}$ deep) with a negligible ambient current while the site 2 is related to a large river ( $200 \mathrm{~m}$ wide, $5 \mathrm{~m}$ deep) with an average ambient current of $10 \mathrm{~cm} / \mathrm{s}$.

Finally, it is useful to note the important advantage of our numerical model to provide direct estimation for the bottom shear stress, $\tau_{b}$. This key parameter for sediment transport is not measured during the field experiment: the time resolution used for S4 records was limited due to the hard drive capacity of the data log; the measurement of velocity near the bed looks problematic if using such a technology. The bottom shear stress $\tau_{b}$ is however accessible from the numerical modelling. With the considered assumptions, the model estimates the bottom shear stress for the day of the 11/08/2006 (site 1) at $0.43 \mathrm{Nm}^{-2}$ and at $1.14 \mathrm{Nm}^{-2}$ for day of the 11/15/2006 (site 2). This last estimated value is very compatible with the values of $\tau_{b}$ founded between 1 and $2 \mathrm{Nm}^{-2}$ from ADV measurements in the Seine estuary (Verney et al., 2007). 

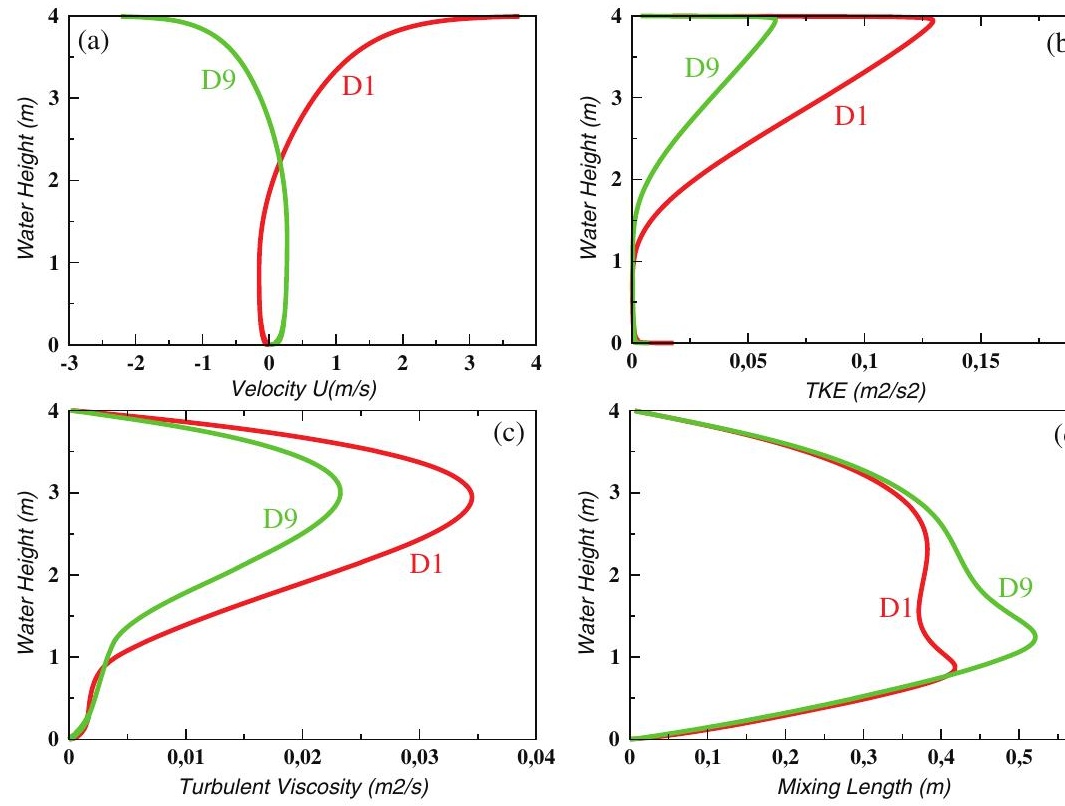


\subsection{Suspension of the sediments induced by boats}

Figure 4 presents time series of SSM concentration measurements from OBS sensor located at $10 \mathrm{~cm}$ from the bottom on site 1 . The confrontation between experiment and simulation presents a good agreement. In particular, the general shape and magnitude of concentration peaks are well reproduced by the computation. The numerical model is therefore able to capture dynamics, the fast mode of erosion and the following slow mode of sedimentation that are produced by a passing boat. As example, figure 4 focusing on the measurements of the 11/10/2006 proposes simulations of the sediment re-suspension peaks. For the peak values, results are in narrow agreement with the measurements performed close to the bed since the difference between the simulated and measured peaks does not exceed $3 \times 10^{-3}$ $g / l$. However, it is also observed in figure 4 some discrepancies between simulation and experiment after the peaks of concentration, i.e. during the sedimentation of the re-suspended matter. This difference with measurements could be explained twofold. On one hand, the numerical model only considers an unique 'equivalent' diameter (40 $\mu \mathrm{m}$ for the site of interest) for the sediment while OBS measurement concerns all the sediment particles whatever their size. As the particle settling velocity scales with the square of its diameter, sediment particles finer than $40 \mu \mathrm{m}$ will remain longer in the suspension so that the simulation results underestimate the concentration during the sedimentation. On the other hand, the numerical model doesn't take account the added turbulence by the propellers effects. These effects could also maintain longer the sediment in suspension.

Despite of its simple assumptions, the actual version of the 1DV model provides practical information for the management plan of the waterway. For example, the amplitude and the time duration of a re-suspension peak are obtained from the model. The time relaxation of the concentration peak is estimated and could be used to avoid cumulative effect whilst increasing the boat frequentation. From figure 4.d, the D59 boat induced peak concentration is decreasing with a characteristic time (noted $\tau$ ) between 10 and $12 \mathrm{mn}$. The following boat shouldn't imply cumulative effect on the D59 peak signature if it passes $15 \mathrm{mn}$ later than D59.

Figure 5.a shows the SSM concentration chronic simulated by the model at the bottom (10 $\mathrm{cm}$ above the bottom) of site 1 . This figure is used to establish a correspondence between the boats passage and the SSM peaks: the peaks succession of the SSM identify with precision the boats causing these peaks (figures. 5.b, 5.c, 5.d). In these figures, we also observe an asymmetry that reflects the rapid phase of erosion and the slow process of sedimentation. This asymmetry has been observed in-situ by others authors (Pham Van Bang et al., 2007; Parchure et al., 2001a; Parchure et al., 2001b). Note that the 1DV model can learn about the amplitudes and duration peaks of SSM without going through any simplifying assumption. Indeed, one can directly read from the SSM concentration figures 5.b, 5.c, 5.d), the characteristic time of decay (or sedimentation). As an example, we read $\tau_{D 22}=220 \mathrm{~s}, \tau_{D 24}=222 \mathrm{~s}$ et $\tau_{D 36}=185 \mathrm{~s}$ respectively for boats D22, D24 and D36. These orders of magnitude are in agreement with the conclusions resulting from the measurements taken on site 1 by Pham Van Bang et al. (2007). On figure 6.a, we present the vertical profiles of the SSM concentration induced by the passage of the D1 and D9 boats (site 1). It is first observed the vertical profiles match in good agreement with the Rouse's law (analytical solution at the equilibrium). It is also observed that the suspension takes predominantly place in the first fifty centimeters from the bottom. Let us remind that return currents due to the boat passage are localized in this zone. As a consequence, an accurate calculation of the return current near the bottom zone is strongly required in the numerical model for a good estimate of the SSM concentration.

The figure 6.b presents the same results as figure 6.a in term of vertical profile of sediment 

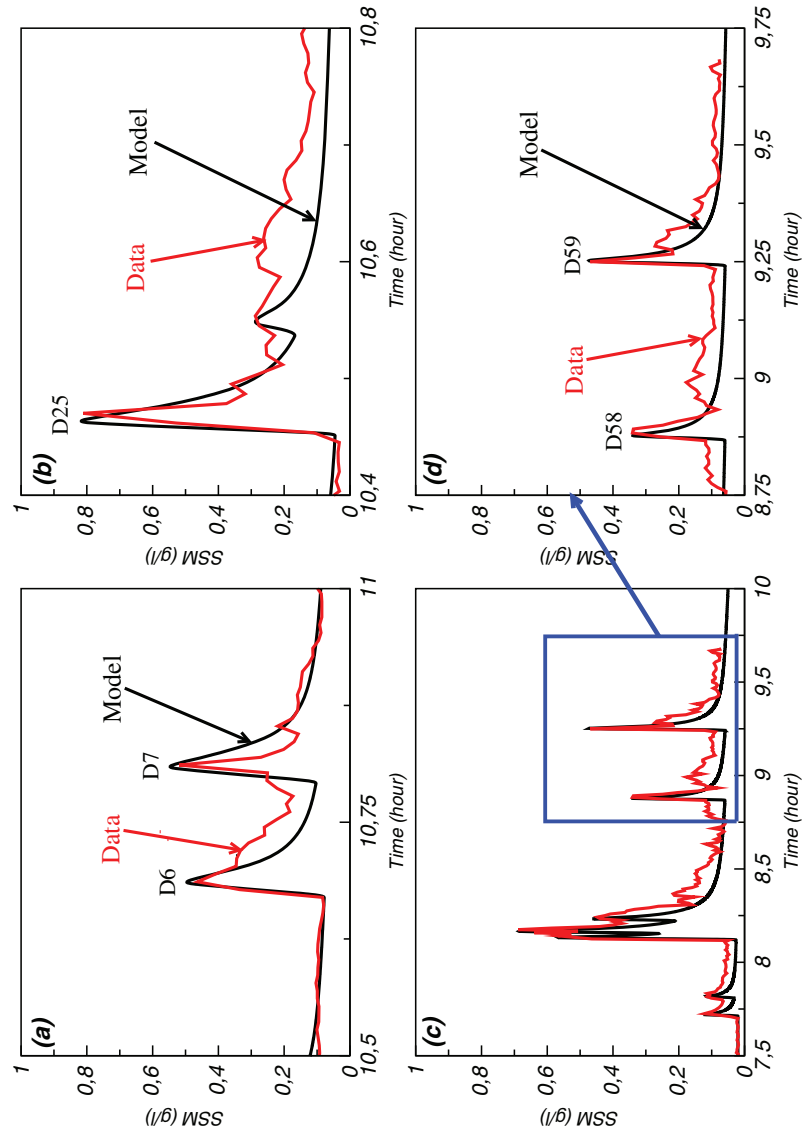

Fig. 4. The SSM chronic issued from simulation.
(a) the peaks of the SSM induced by boats D6 and D7 11/08/2006.
(b) the peaks of the SSM induced by boat D25 11/09/2006.
(c) the peaks of SSM induced by all river traffic 10/11/2006.
(d) zoom on the SSM induced by boats D58 and D59 11/10/2006 


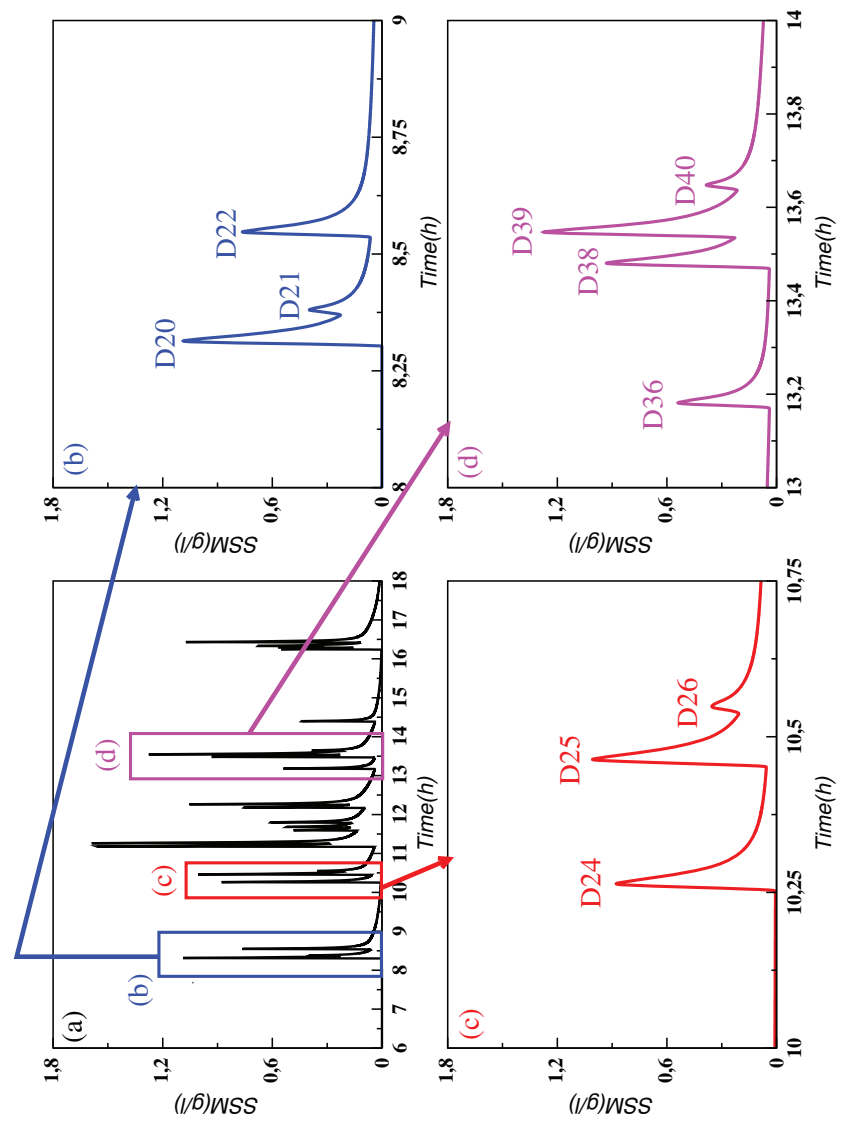

Fig. 5. The SSM chronic issued from simulation.

(a) the peaks of SSM induced by all river traffic of 11/09/2006.

(b), (c) and (d) identification of boats causing the SSM peaks 
horizontal fluxes (u.c). As a consequence of the previously detailed velocity $(u$, in figure 3.a) and concentration profiles ( $c$, in figure 6.a), the vertical distribution of sediment fluxes presents positive and negative values depending on the direction of the passing boat. More important values of the sediment fluxes occur close to the bottom and near the free surface. The results presented in figure 6.b provide again practical information for the management
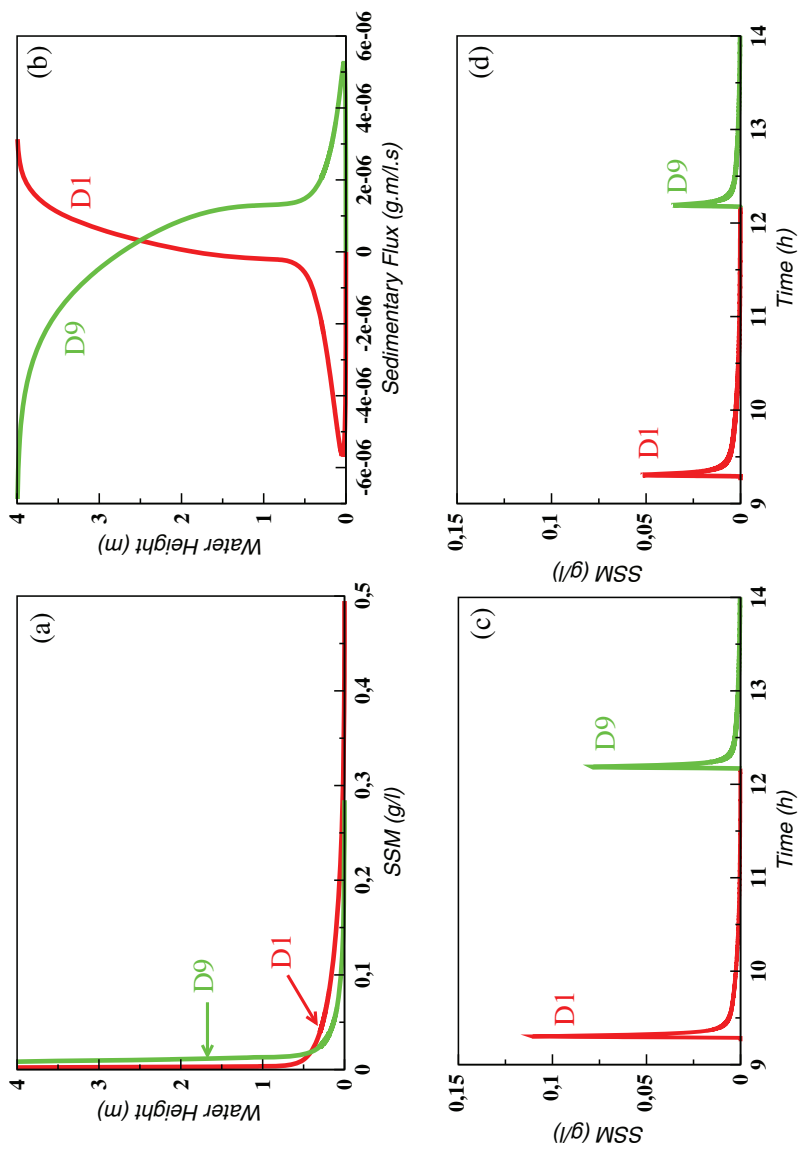

Fig. 6. The SSM chronic issued from simulation.

(a) the peaks of SSM induced by all river traffic of 11/09/2006.

(b), (c) and (d) identification of boats causing the SSM peaks 
of the waterway. The net sediment transport induced by daily traffic could be estimated as follows. For the daily traffic recorded during the day of the 11/9/2006, the vertical profiles of the sediment concentration induced by each passing boat is integrated along the vertical. The net sediment mass transported per second and per width unit (figure 7) is therefore obtained. For the whole traffic (17 boats, site 1 ) of the 11/9/2008, the sediment transport is estimated by the model at $0.280 \mathrm{kgm}^{-1} \mathrm{~s}^{-1}$ and $2.940 \mathrm{kgm}^{-1} \mathrm{~s}^{-1}$ for the day of the $11 / 15 / 2006$ (site 2). An extrapolation of these results at one year gives the estimate of $102.5 \mathrm{~kg}$ per year and per width unit for site 1 (and 1.1 tons per year and width unit for site 2). Finally, the estimate of the net mass transported due to navigation traffic is proposed in table 3 for other days.

\begin{tabular}{|ll|ll|}
\hline \multicolumn{2}{|c|}{ Site 1} & \multicolumn{2}{c|}{ Site 2} \\
\hline $11 / 08 / 2006:$ & $1.720 \mathrm{Kgm}^{-1}$ & $11 / 14 / 2006:$ & missing data \\
\hline $11 / 09 / 2006:$ & $0.280 \mathrm{Kgm}^{-1}$ & $11 / 15 / 2006:$ & $2.943 \mathrm{Kgm}^{-1}$ \\
\hline $11 / 10 / 2006:$ & $0.124 \mathrm{Kgm}^{-1}$ & $11 / 16 / 2006:$ & $2.475 \mathrm{Kgm}^{-1}$ \\
\hline
\end{tabular}

Table 3. Net mass of the sediments transported by suspension per day during de measurements period (November 2006)

\section{Conclusions}

Predicting the sediment transport in natural environment is a difficult task, but an essential exercise for ecological and economical issues. More difficult is the prediction of sediment transport in presence of navigation traffic. To study this peculiar case, a field experiment on two different sites is conducted with the measurement on the sediment re-suspension induced by passing boats.

In the continuity of this work, we developed a 1DV numerical model. Despite of its apparent simplicity, the model considers all the governing processes (hydrodynamic, turbulence, sediment transport) to compute the boat induced sediment transport. Although based on simplifying assumptions, this model recovers all the flow characteristics that are observed in the under keel clearance zone, meanwhile propeller effects are neglected.

The use of the developed model, this study demonstrates that the numerical model is able to predict reasonably all the measured variables. Moreover, the model provides precious information on the flow variables difficult to measure due to the complexity of their achievement in field conditions. More particularly, the 1DV model supplies information on turbulence, bottom stress shear, sedimentary flux. The model gives also estimation that could be used for an integrated management of the waterway.

Finally, let us note that the actual version of the model doesn't account for the total flow in the under keel clearance zone, nor for muddy sediment transport. A non-hydrostatic 2DV or 3D numerical model (hydrodynamic, turbulence, muddy sediment transport) is needed for a more realistic study of the flows including the propeller effects.

\section{Acknowledgement}

The authors acknowledged gratefully the Inland Waterways for France VNF (Voies Navigables de France), the University of Quebec and the Regional Laboratory of the Parisian East (LREP) for their financial and technical support during the field investigations 


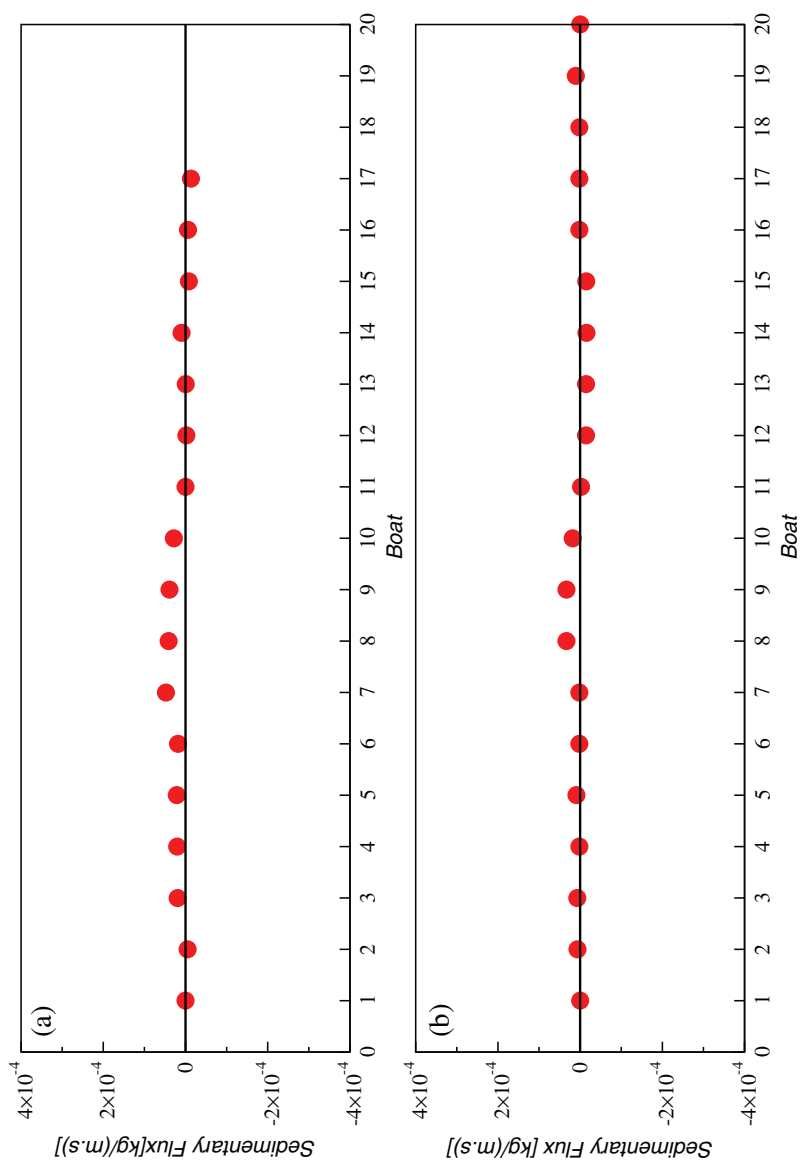

Fig. 7. Suspended sedimentary flux induced by boats at site 1 .

a) daily river traffic of $11 / 08 / 2006$

b) daily river traffic of $11 / 09 / 2006$ 


\begin{tabular}{|c|c|c|c|c|c|c|}
\hline Date & H (GMT) & Reference & C.E & Length $(\mathrm{m})$ & Direction & Speed $(\mathrm{km} / \mathrm{h})$ \\
\hline $11 / 08 / 2006$ & $09 \mathrm{~h} 45$ & D1 & E & 38 & Douai & 13.5 \\
\hline- & $10 \mathrm{~h} 45$ & D6 & C & 45 & Douai & 08.5 \\
\hline- & $10 \mathrm{~h} 55$ & D7 & E & 80 & Cambrai & 06.6 \\
\hline- & $12 \mathrm{~h} 20$ & D9 & E & $2 \times 38$ & Cambrai & 08.0 \\
\hline $11 / 09 / 2006$ & $08 \mathrm{~h} 18$ & D20 & C & - & Douai & 11.0 \\
\hline- & $08 \mathrm{~h} 22$ & D21 & - & - & Cambrai & 05.8 \\
\hline- & $08 \mathrm{~h} 32$ & D22 & C & 38 & Douai & 10.0 \\
\hline- & $10 \mathrm{~h} 15$ & D24 & C & 38 & Douai & 10.5 \\
\hline- & $10 \mathrm{~h} 27$ & D25 & E & 80 & Cambrai & 10.0 \\
\hline- & $10 \mathrm{~h} 32$ & D26 & E & 85 & Cambrai & 06.5 \\
\hline- & $12 \mathrm{~h} 55$ & D36 & C & 67 & Douai & 09.7 \\
\hline- & $13 \mathrm{~h} 28$ & D38 & C & 38 & Cambrai & 10.0 \\
\hline- & $13 \mathrm{~h} 32$ & D39 & C & 90 & Douai & 11.0 \\
\hline- & $13 \mathrm{~h} 38$ & D40 & E & 80 & Cambrai & 06.0 \\
\hline $11 / 10 / 2006$ & $08 \mathrm{~h} 05$ & D58 & C & 38 & Douai & 06.5 \\
\hline- & $09 h 15$ & D59 & C & 79 & Douai & 09.7 \\
\hline
\end{tabular}

Table 4. Information about some boats cited in the text:

C.E : Carrying or Empty boat.

Direction (see figure 1): Douai = downstrean; Cambrai = upstream

\section{References}

Blumberg A.F. \& Mellor G.L. (1987). A description of three-dimensional coastal ocean circulation model has. In: Three-Dimensional Coastal Models Ocean, Coastal and Estuarine Sciences, Volume 4 AGU N.S. Heaps (Ed.), pp 1-16, Washington (D.C.).

Celik, I. \& Rodi W. (1984). A deposition-entrainment model for suspended sediment transport. Report SFB 210/T/6, University of Karlsruhe (FRG), Karlsruhe, Germany, 55 p.

Celik, I. \& Rodi W. (1988). Modeling suspended sediment-transport in nonequilibrium situations. ASCE Journal of Hydraulic Engineering, Vol. 114, No. 10, October 1988, 1157-1191.

Celik, I. \& Rodi W. (1991). Suspended sediment-transport capacity for open Chanel flow. ASCE Journal of Hydraulic Engineering, Vol. 117, No 2, February 1991, 191-204.

Parchure, T.M.; McAnally W.H. \& Teeter A.M. (2001a). Desktop method for estimate vessel-induced sediment suspension. ASCE Journal of Hydraulic Engineering, Vol. 127, No 7, July 2001, 577-587.

Parchure, T.M.; McAnally W.H. \& Teeter A.M. (2001b). Wave-induced sediment resupension near the shorelines of the upper the Mississippi to rivet system. (ENV Report 20), $99 \mathrm{p}$

Pham Van Bang, D.; Ouahsine, A.; Sergent, P. \& Hissel, F. (2007). Impact of the passage of the boats on the transport of the sediments and the maintenance of the inland waterways: measurements and analyzes. Report VNF, UTC, CETMEF, $63 \mathrm{p}$.

Pham Van Bang, D.; Ouahsine, A.; Sergent, P.; Long, B.; Montreuil S.; Debaillon P. \& Hissel F. (2008). Erosion of the sediments and vagueness generated by the passage of

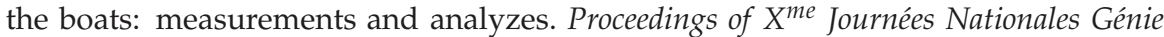
Côtier-Génie-Civil, pp. 605-614, ISBN 2-9505787-9-9, Sophia Antipolis, October 2008, Centre Français du Littoral, France 
Van Rijn, L.C. (1986). Mathematical modeling off suspended sediment in non-uniform flows. ASCE Journal of Hydraulic Engineering, Vol. 12, No 6, June 1986, 1613-1641.

Verney R.; Deloffre, J.; Brown-Cottan J.C.; Lafite R.(2007). Intertidal The effect off wave-induced turbulence one mudflats: impact off boat traffic and wind. Continental Shelf Reseach, Vol 27, No 5, March 2007, 594-612. 


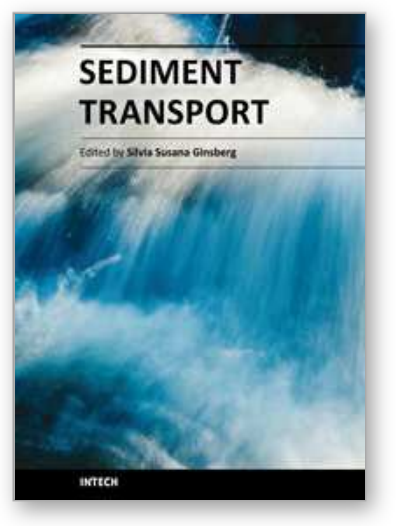

\author{
Sediment Transport \\ Edited by Dr. Silvia Susana Ginsberg
}

ISBN 978-953-307-189-3

Hard cover, 334 pages

Publisher InTech

Published online 26, April, 2011

Published in print edition April, 2011

Sediment transport is a book that covers a wide variety of subject matters. It combines the personal and professional experience of the authors on solid particles transport and related problems, whose expertise is focused in aqueous systems and in laboratory flumes. This includes a series of chapters on hydrodynamics and their relationship with sediment transport and morphological development. The different contributions deal with issues such as the sediment transport modeling; sediment dynamics in stream confluence or river diversion, in meandering channels, at interconnected tidal channels system; changes in sediment transport under fine materials, cohesive materials and ice cover; environmental remediation of contaminated fine sediments. This is an invaluable interdisciplinary textbook and an important contribution to the sediment transport field. I strongly recommend this textbook to those in charge of conducting research on engineering issues or wishing to deal with equally important scientific problems.

\title{
How to reference
}

In order to correctly reference this scholarly work, feel free to copy and paste the following:

Hassan Smaoui, Abdellatif Ouahsine, Damien Pham Van Bang, Philippe Sergent and François Hissel (2011). Numerical Modelling of the Sediment Re-Suspension Induced by Boat Traffic, Sediment Transport, Dr. Silvia Susana Ginsberg (Ed.), ISBN: 978-953-307-189-3, InTech, Available from:

http://www.intechopen.com/books/sediment-transport/numerical-modelling-of-the-sediment-re-suspensioninduced-by-boat-traffic

\section{INTECH}

open science | open minds

\section{InTech Europe}

University Campus STeP Ri

Slavka Krautzeka 83/A

51000 Rijeka, Croatia

Phone: +385 (51) 770447

Fax: +385 (51) 686166

www.intechopen.com

\section{InTech China}

Unit 405, Office Block, Hotel Equatorial Shanghai

No.65, Yan An Road (West), Shanghai, 200040, China

中国上海市延安西路65号上海国际贵都大饭店办公楼405单元

Phone: +86-21-62489820

Fax: +86-21-62489821 
(C) 2011 The Author(s). Licensee IntechOpen. This chapter is distributed under the terms of the Creative Commons Attribution-NonCommercialShareAlike-3.0 License, which permits use, distribution and reproduction for non-commercial purposes, provided the original is properly cited and derivative works building on this content are distributed under the same license. 